\title{
of labor
}

\section{Padma Raj Dhungana $^{1}$, Rajesh Adhikari ${ }^{1}$, Prem Raj Pageni ${ }^{2}$, Apsara Koirala ${ }^{3}$, Anand Nepal ${ }^{4}$}

1 Department of Obstetrics and Gynecology, Pokhara Academy of Health Sciences, Western Regional Hospital, Nepal

2 Matrisishu Miteri Hospital, Batulechaur, Pokhara, Nepal

3 Nobel Academy of Health Sciences, Department of Pharmacology, Pokhara, Nepal

4 Department of Dermatology, Pokhara Academy of Health Sciences, Western Regional Hospital, Nepal

\section{Correspondence:}

Dr. Padma Raj Dhunagana, MD

Department of Obstetrics and Gynecology Pokhara Academy of Health Sciences

Western Regional Hospital

Pokhara, Nepal

Email: dhunganapadma@gmail.com

Article received : $18^{\text {th }}$ July 2018

Article accepted : $2^{\text {nd }}$ Aug. 2018

\section{ABSTRACT}

\section{Background:}

Labor is a naturally occurring physiological process associated with uterine contractions, effacement, dilatation of cervix and descent of presenting part. Drotaverine hydrochloride is a non-anticholinergic isoquinoline derivative which acts by elevating intracellular cyclic Adenosine Mono Phosphate (cAMP) and cyclic Guanosine Mono Phosphate (cGMP) promoting smooth muscle relaxation. Materials And Method: This was a hospital based prospective study on effectiveness of Drotaverine Hydrochloride on enhancing dilatation of cervix and acceleration of active phase of labor. The sample size was 100 . Fifty cases of women in active phase of labor received injection drotaverine hydrochloride 40 $\mathrm{mg}$ (group i) and fifty cases of women did not receive any drug (group ii) among those at term with singleton pregnancy and vertex presentation. Variables like maternal age, interval between administration of drug and delivery, mode of delivery, apgar score at 5 minutes, NCU (Neonatal Care Unit) admission and neonatal outcomes were recorded. Data analysis was done with the help of SPSS program. Results: The mean interval between drug adminstration to delivery in primipara and multipara in group i was 3.05 hours and 2.31 hours while in group ii was 4.5 hours and 3.75 hours respectively. The mean interval between drug adminstration and delivery was shorter in both groups of multipara. In group i, $96 \%$ had normal delivery and $4 \%$ had vaccum delivery and in group ii $90 \%$ and $10 \%$ had normal delivery and vacuum delivery respectively. None of the participants had caeseraian section. There were no perinatal mortalities. Conclusion: The administration of drug Drotaverine Hydrochloride is effective in shortening duration of labor with favorable feto-maternal outcome.

Keywords: Cervical Dilatation, Drotaverine Hydrochloride, Labor acceleration. 


\section{INTRODUCTION}

Labor is a natural physiological process, characterized by progressive increase in frequency, intensity and duration of uterine contractions associated with effacement and dilatation of cervix with descent of the fetus through the birth canal. Prolongation of labor may result into increased perinatal loss and infant mortality and morbidity apart from psychological trauma to the mother. ${ }^{1}$ The rate of cervical dilatation is one of the most important factor that determines the duration of labor and is the result of all driving force of uterine contraction acting against passive tissue resistance. ${ }^{2}$

Labor is a multifactorial process which involves myometrial contraction, cervical ripening and dilatation, expulsion of fetus and placenta in an orderly manner. The first stage of labor lasts for about 12-16 hours in primigravida and for 6-8 hours in multigravida. ${ }^{3}$ Active phase of labor is said to commence when cervical dilatation is of $3-4 \mathrm{~cm}$ or more in the presence of regular uterine contraction. Active phase in nulli-para lasts for an average of 5 hours, where as in multi-para it is 3.5 hours. The abnormal progress of labor is primarily of two categories - protraction disorder and arrest disorder. Protraction is the slow rate of cervical dilatation of less than $1.2 \mathrm{~cm}$ per hour or descent of head less than $1 \mathrm{~cm}$ per hour in case of primigravida and cervical dilatation less than $1.5 \mathrm{~cm}$ per hour or descent of head less than $2 \mathrm{~cm}$ per hour in multi-para. Arrest is the complete cessation of cervical dilatation and descent of head. Arrest of dilatation is ascertained when no cervical changes occurs for 2 hours and arrest of descent means no descent of head for an hour. ${ }^{4}$

Painless and short labor is desired by every mother and every caretaking obstetrician. Labor progress depends upon the strength and frequency of uterine contractions and simultaneous active cervical dilatation. ${ }^{5}$ However, sometimes active cervical dilatation lags behind even in the presence of uterine contraction and might result in undue painful, prolonged labor affecting both maternal and fetal health. Therefore, pharmacological agents are used to facilitate the cervical dilatation in harmony with good uterine contractions for smooth progress of labor. ${ }^{6}$ There are various mechanical and pharmacological methods by which cervical dilatation can be facilitated. Early amniotomy augments labor and shortens the
Journal of Pokhara Academy of Health Sciences Vol. 2 Issue 3 Jan-June 2019 duration of labor. ${ }^{3}$ Smooth muscle relaxants are well accepted for use in facilitating progression of labor. Smooth muscle relaxant acts as spasmolytics and inhibit spasm of cervical smooth muscle causing effective cervical dilatation. Various agents have been used to overcome cervical muscle spasm. ${ }^{1}$

An ideal antispasmodic for acceleration of cervical dilatation should have a prompt and long lasting action, no adverse effects on uterine contractility, and should be free from the risk of uterine inertia. It should also have minimal adverse effects to the mother and fetus. ${ }^{4}$ Recently newer drug, drotaverine hydrochloride, an isoquinolone with excellent spasmolytic effect has been used to shorten the duration of labour and excellent result have been reported. ${ }^{3}$ Drotaverine is a non-anticholinergic iso-quinoline derivative. It acts by inhibiting phosphodiesterase- 4 selective to smooth muscle, elevates intracellular cAMP and cGMP and promotes smooth muscle relaxation due to change in membrane ionic fluxes and membrane potential. It has been used orally as well as parenterally for intestinal, renal, bilary and uterine spasms and do not have anticholinergic side effects. Adverse effect reported are headache, dizziness, constipation, flushing and hypotention. ${ }^{2}$ is mainly excreted by non-renal route and has half-life of 7-12 hours. $^{7}$

\section{MATERIALS AND METHOD}

This was a hospital based prospective comparative study. The study was conducted at Western Regional Hospital, Pokhara, a tertiary level hospital. Duration of study was three months. Data were collected from $1^{\text {st }}$ May to $31^{\text {st }}$ July, 2014 after getting permission from hospital authority.

Pregnant women at term with singleton vertex presentation and spontaneous onset of labor with active phase having 3 uterine contractions in 10 minutes and cervical dilatation of $4 \mathrm{~cm}$ or more with intact membrane were enrolled in the study. Informed consents were taken. Total of 100 cases were enrolled in the study. Fifty patients were given injection drotaverine hydrochloride (40 mg) intravenously (group i) and 50 patients were not given drotaverine hydrochloride (group ii).

Pregnant women with multiple fetuses, fetal demise or fetal anomaly, pre-eclampsia, eclampsia, chronic 
systemic diseases such as diabetes mellitus and hypertension, induced labor or augmented labor, preterm labor and premature ruptures of membrane were excluded from the study.

General and systemic examinations were done. Per abdominal examination was done to note the height of the uterus, presentation, frequency and intensity of contractions and descent of head. Fetal well-being was monitored by noting the rate and regularity of Fetal Heart Sound (FHS). Vaginal examination was done to find out and note the cervical effacement, cervical dilatation, consistency of cervix, station of presenting part and status of amniotic membrane. Pelvic assessment was done to exclude any obvious cephalo-pelvic disproportion. Investigations including Hemoglobin level, Blood group and Random Blood Sugar (RBS) were done .

Patients were asked to rest in left lateral position and inform the duty doctor if she had any unwanted effects. Continuous monitoring of maternal and fetal conditions were done by duty doctor/duty staff. Fetal heart rate was recorded every half an hour in early active first stage of labor and every 15 minutes in advanced first stage of labor. In the second stage, fetal heart rate was recorded every five minutes and in the pushing phase after every contraction. Per vaginal examination was done every 4 hours. State of cervix including effacement, dilatation, consistency, descent of presenting part and status of amniotic membrane were noted during each examination. Time of membrane rupture, nature of liquor and time of full dilatation were also noted. All the progress of labor were graphically recorded in Partograph.

Hospital protocol was followed in cases of slow progress of labor. Amniotomy with or without syntocinone drip was used in cases of slow progress of labor.

Mother and baby were followed up till discharge. Data analysis was done using SPSS program and was depicted as tables, diagrams, and chart.

\section{RESULTS}

Our study revealed that there was no significant difference in age group between two groups. Most of the women were in the age group of $20-24$ years (55\%), $24 \%$ were in the age group $25-29$ years, $11 \%$ in less than 19 years group and $10 \%$ in more than 30 years group (figure 1).
Figure 1. Age distribution

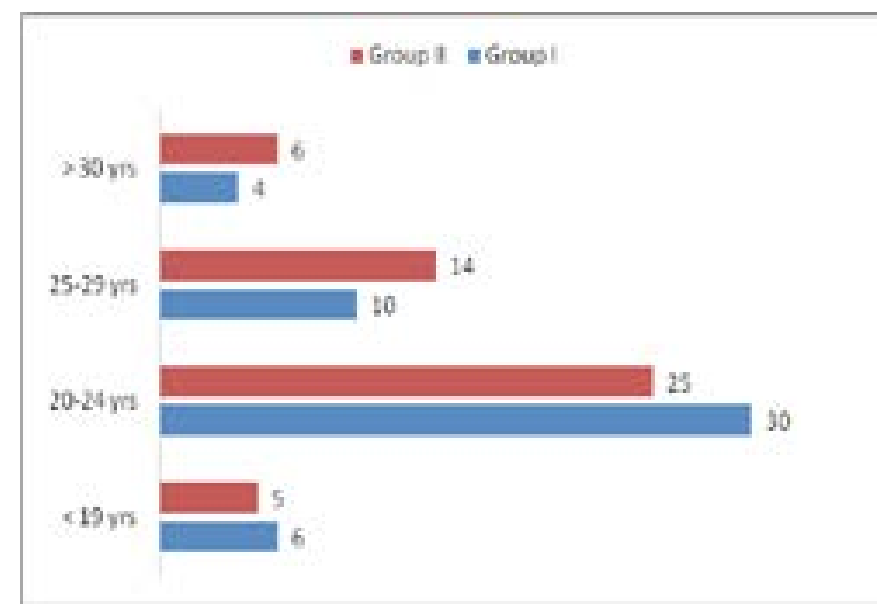

Total duration of time taken from administration of drotaverine up to delivery was recorded in hours. In group $i$ the time taken in primipara was $2.4-4.1$ hours (mean $3.05 \mathrm{hrs}$ ) and $1.18-2.6 \mathrm{hrs}$ (mean $2.31 \mathrm{hrs}$ ) in multipara. In group ii it was $2.36-6.21 \mathrm{hrs}$ in primipara (mean 4.45 hrs) and 3.1-4.4 hrs (mean 3.75hrs) in multipara mean. There was significant difference in interval between administration of drug to delivery among the two groups in both primipara and multipara (Figure 2).

Figure 2. Administration of Drug to delivery interval

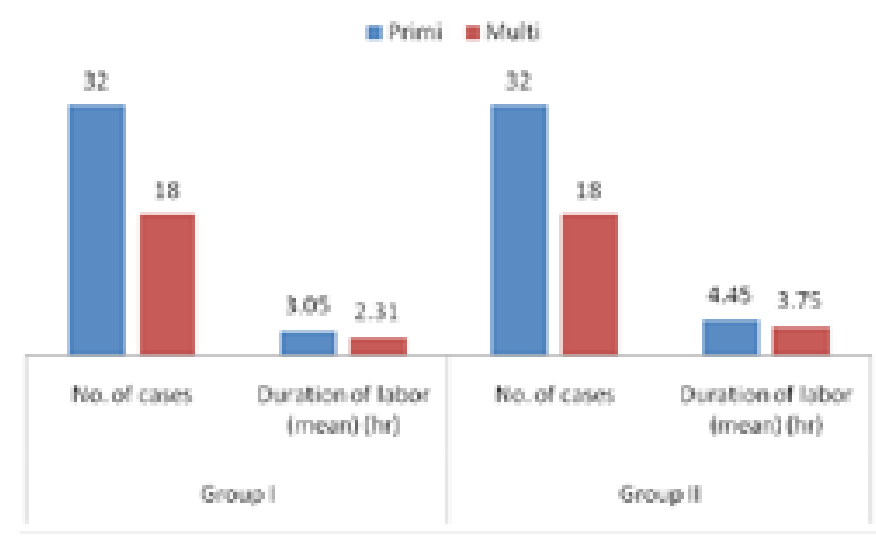

In our study five Patient (10\%) in group i required oxytocin augmentation without amniotomy and ten patient (20\%) in group ii needed oxytocin augmentation among which three cases also required amniotomy. (Table 1)

In group i, 2 cases had vacuum delivery for fetal distress in second stage of labor while 5 cases ( 2 for prolonged second stage and 3 for fetal distress) had vacuum delivery in group ii.

Two babies were admitted for meconium aspiration syndrome in group i, 2 babies with birth asphyxia and 3 babies with meconium aspiration syndrome were 
Original Article

admitted to NCU in group ii (Table 2).

Table 1: Need for augmentation of labor by amniotomy with or without syntocinon

\begin{tabular}{|l|c|c|c|c|}
\hline \multirow{2}{*}{ Augumentation With } & \multicolumn{2}{|c|}{ Group i } & \multicolumn{2}{|c|}{ Group ii } \\
\cline { 2 - 5 } & N & $\%$ & N & $\%$ \\
\hline Amniotomy & 00 & 00 & 3 & 6 \\
\hline Syntocinone & 5 & 10 & 10 & 20 \\
\hline
\end{tabular}

Table 2: Admission of newborn in NCU

\begin{tabular}{|c|c|c|c|c|}
\hline & \multicolumn{2}{|c|}{ Group i } & \multicolumn{2}{c|}{ Group ii } \\
\cline { 2 - 5 } $\begin{array}{c}\text { Neonatal Outcome } \\
\text { Admission to NCU }\end{array}$ & $\mathrm{N}$ & $\%$ & $\mathrm{~N}$ & $\%$ \\
\hline Birth Asphyxia & 00 & 00 & 2 & 4 \\
\hline $\begin{array}{c}\text { Meconium aspiration } \\
\text { Syndrome }\end{array}$ & 2 & 4 & 3 & 6 \\
\hline
\end{tabular}

All babies were born alive. Total 7 babies from both groups were admitted but there was no any neonatal mortality in the study (Table 3).

\section{Table 3: Neonatal Outcome}

\begin{tabular}{|l|c|c|c|c|}
\hline \multicolumn{1}{|c|}{ Neonatal Outcome } & \multicolumn{2}{|c|}{ Group i } & \multicolumn{2}{c|}{ Group ii } \\
\hline & $\mathrm{N}$ & $\%$ & $\mathrm{~N}$ & $\%$ \\
\hline Alive & 50 & 100 & 50 & 100 \\
\hline Still Birth & 00 & & 00 & \\
\hline Neonatal Death & 00 & & 00 & \\
\hline
\end{tabular}

\section{DISCUSSION}

In this study there was no significant difference in age group between the two groups. No side effects were observed in patients who received drotaverine hydrochloride.

There was significant difference in time interval between drug adminstration to delivery in the two groups. The mean interval between drug adminstration to delivery was shorter in cases of multipara in comparision to primipara in both groups. The mean duration in primipara was shorter in the drotaverine group compared to the primipara in the control group. Similar observation was found by Sharma JB et $\mathrm{al}^{3}$ where the mean injection to delivery interval was 194 min in primipara and 412.8
Journal of Pokhara Academy of
in control group.

The duration of labor was markedly reduced also in the study reported by Thapa $\mathrm{M}$ et $\mathrm{al}^{8}$ where the mean duration of injection to delivery interval in drotaverine group for primigravidae and multigravidae was 196.9 min and $127 \mathrm{~min}$ respectively.

Decrease in first stage of labor can be attributed to the action of drotaverine. Study by Veronica Irene Yuel et et al. ${ }^{9}$ have shown drotaverine hydrochloride to be a superior cervical dilatating agent than other antispasmodics like epidosin or buscopan. Majumder $\mathrm{S}$ et.al. ${ }^{10}$ concluded that drotaverine causes more rapid acceleration and in their study the first stage of labor was $176.67+/-91.69 \mathrm{~min}$.

In group i of our study, two had vacuum delivery for fetal distress in second stage of labor while 5 cases had vacuum delivery in group ii ( 2 for prolonged second stage and 3 for fetal distress). None of the cases in any of the two group had cesarean section. This may be due to the fact that the cases selected were already in established labor and they had no other high risk factors. The mode of delivery in drotaverine group of our study was vaginal in $100 \%$ of the cases which is similar to J.B. Sharma et. $\mathrm{al}^{3}$. But in another similar study by Tripti $\mathrm{N}$ et.al ${ }^{11} 93 \%$ cases of the drotaverine group had spontaneous vaginal delivery, $6 \%$ had forcep delivery ( 5 for fetal distress and 1 for prolong $2^{\text {nd }}$ stage) and $1 \%$ had cesarean section (for fetal distress). Sachin K Ajmera ${ }^{12}$ gave drotaverine in active phase of labor and the mode of delivery in drotaverine group was $96 \%$ vaginal, $3 \%$ cesarean, and $1 \%$ operative vaginal. Gupta $\mathrm{B}$ et al ${ }^{13}$ found that among 49 cases receiving drotaverine 47 cases had normal vaginal, and 2 cases had forceps delivery. Our findings of vaginal delivery as predominant mode of delivery is similar to these studies and is likely due to careful selection of the cases.

There was no baby with apgar score less than 3 in both group. There were 2 babies delivered by vacuum for fetal distress in group i. Five babies had apgar score less than 7 in group ii. There was no statistical significant difference in apgar score among the two groups. Similar observation was also found by Sachin K Ajmera et al. ${ }^{12}$ In Group i, 2 babies were admitted for meconium aspiration syndrome while in group ii, 2 babies with birth asphyxia and 3 babies with meconium aspiration 
syndrome were admitted to NCU. All babies were born alive. There was no any neonatal mortality.

\section{CONCLUSION}

The administration of drug drotaverine hydrochloride is effective in shortening duration of active phase of labor in both primigravidae and multigravida with no major fetomaternal side effects. The drug is safe when used in pharmacological doses and do not produce any untoward effect to the fetus. Thus we can conclude that drotaverine is the drug of choice in management of labor for a convenient and shorter delivery. Further large well controlled studies are needed.

\section{REFERENCES}

1. Tiwari AK, Rajpoot A, Singhal M, Shah H, Bairwa R, Songara RK. Significant combination of preferential cox-2 inhibitor and nonanticholinergic spasmolytic used in labor augmentation. Pharmacologyonline 2011;2:470476.

2. Tripathi KD. Antichoinergic drug and drug acting on autonomic gangalia. Essential of medical pharmacology. $6^{\text {th }}$ ed. Jaypee brother's medical publishers Ltd. New Delhi 2008; p.111-12.

3. Sharma JB, PundirP, Kumar A, Murthy NS. Drotaverine hydrochloride vsvalethamate bromide in acceleration of labor. Int Journal of Gynaecology\& Obstetrics 2001;74:255-260.

4. NaquiSB, HaroonZUN. Efficacy and safety of drotaverine and phloroglucinol in first stage of labor. Pak J Surg 2011;27(1):39-43.

5. O Dricoll K, Stronge JM, Minogue M. Active management of labor. Br Med J 1973; 3:135-137.

6. Ashok KB In search of efficacy of valethamate bromide, a cervical dilator: review of global medicine and healthcare research (RGMHR) 2011; 2(1):17-21.

7. Singh KC, Jain P, Goel N, Saxena A. Drotaverine hydrochloride for augmentation of labour. Int $\mathrm{J}$ GynaecolObstet 2004; 84:17-22.

8. Thapa M, Saha R, Pradhan A, Shrestha S. Effect of drotaverine hydrochloride in progress of labor. Nepal J ObstetGynaecol 2007Nov-Dec; 2(2):911.

9. Yuel V I, Kaur V, Kaur D. Programmed labor for optimizing labor and delivery. JK Science 2008 April-June; 10(2):62-64.

10. Majumder S, Ray J, Baidya, Rakshit A, Kumar SN . Comparative study of drotaverine hydrochloride and valethamate bromide in active management of labor. Journal OfPaediatricsObstetrice and Gynaecology 2010 November; 1(11):416-420.

11. Tripti N, Jyoti J. To compare and evaluate the efficacy and safety of drotaverine and valethamatebromidae. J ObstetGynecol India 2009; 54:324-331.

12. Mercer BM, McNanley T, O’ Brien JM, Randal L, Sibai BM. Early versus late amniotomy for labor induction: a randomized trial. Am J ObstetGynecol 1995; 173(4):1321-1325.

13. Gupta B, Neelone V, Mittal S. Drotaverine hydrochloride versus Hyoscine-N-butylbromide in augentaton of labor. International Journal of Gynecology and Obstetrics 2008; 100:244-247. 